\title{
BCP Regimen
}

National Cancer Institute

\section{Source}

National Cancer Institute. BCP Regimen. NCI Thesaurus. Code C9524.

A chemotherapy regimen consisting of carmustine, cyclophosphamide, and prednisone that may be used in the treatment of plasma cell myeloma. 